\title{
HUBUNGAN ANTARA KOMUNIKASI INTERPERSONAL DENGAN KEBUTUHAN AFILIASI SISWA KELAS VIII SMP NEGERI 1 BANDUNGAN KABUPATEN SEMARANG TAHUN AJARAN 2018/2019
}

\author{
Fajar Rizky Saputra ${ }^{1}$ Umbu Tagela $^{2}$ Setyorini $^{3}$ \\ Email: 132015604@student.uksw.edu ${ }^{1}$, umbu.tagela.fkip@gmail.com², \\ setyorini@uksw.edu ${ }^{3}$ \\ Program Studi Bimbingan dan Konseling FKIP - Universitas Kristen Satya Wacana \\ Salatiga
}

\begin{abstract}
Abstrak
Penelitian ini dilaksanakan di SMP Negeri 1 Bandungan Kabupaten Semarang khususnya kelas VIII, pengambilan subyek penelitian menggunakan teknik total sampling yaitu pengambilan sampel menggunakan semua peserta didik kelas VIII SMP Negeri 1 Bandungan Kabupaten Semarang sebagai subyek penelitian yang berjumlah 140 peserta didik. Penelitian ini bertujuan untuk mengetahui hubungan signifikan antara komunikasi interpersonal dengan kebutuhan afiliasi peserta didik kelas VIII SMP Negeri 1 Bandungan Kabupaten Semarang. Alat ukur yang digunakan dalam penelitian ini adalah Skala Komunikasi Interpersonal yang disusun oleh Lydia Christiani (2017) mengacu pada teori Devito (2011), dan Skala Kebutuhan Afiliasi disusun oleh Yanica Nur Layla (2014) mengacu pada teori McClelland (1987). Teknik analisis data yang digunakan dalam penelitian ini adalah Korelasi Kendall's tau b dengan menggunakan program SPSS for windows release 20.0. Dari hasil analisis data diperoleh hasil bahwa ada hubungan yang sangat signifikan antara komunikasi interpersonal dengan kebutuhan afiliasi pada peserta didik kelas VIII SMP Negeri 1 Bandungan Kabupaten Semarang dengan hasil koefisien korelasi $r_{x y}=, 976$ pada taraf koefisien signifikansi $0,000<0,050$. Artinya bila komunikasi interpersonal naik akan diikuti dengan naiknya kebutuhan afiliasi pula. Dengan demikian tujuan penelitian dapat dicapai.
\end{abstract}

Kata Kunci: Komunikasi Interpersonal, Kebutuhan Afiliasi

PENDAHULUAN

Kehidupan manusia tidak akan lepas dari sebuah komunikasi, baik yang bersifat verbal maupun non verbal. Komunikasi sendiri berlangsung dalam berbagai konteks, mulai dari komunikasi interpersonal, komunikasi intrapersonal, komunikasi kelompok, komunikasi organisasi sampai dengan komunikasi massa. Masing-masing konteks memiliki keistimewaan yang semuanya menghendaki adanya efektivitas dalam prosesnya.

Abraham Maslow (2004) mengusulkan gagasan bahwa tujuan manusia berkomunikasi adalah untuk memenuhi berbagai kebutuhan, ide ini merupakan pengembangan dari gagasan Schutz.

Menurut Maslow, kebutuhan dasar harus dipenuhi terlebih dahulu sebelum fokus pada kebutuhan lain yang lebih abstrak. Kebutuhan pokok manusia yang diidentifikasi Maslow dalam urutan kadar pentingnya yaitu kebutuhan fisiologis (basic needs), kebutuhan akan rasa aman (security needs), kemudian dikaitkan dengan kebutuhan afiliasi yaitu kebutuhan akan perasaan diterima dalam lingkungannya, kebutuhan akan perasaan dihormati. Kebutuhan penghargaan (esteem needs), dan kebutuhan perwujudan diri (self actualization). 
Kebutuhan tersebut haruslah dipenuhi agar tiap-tiap individu dapat merasakan kebahagiaan yang diinginkan. Setiap kebutuhan tersebut pastinya berkaitan dengan orang lain tidak mungkin seseorang memenuhi kebutuhan tersebut dengan sendirinya, oleh karena itu yang peling utama di antara kelima kebutuhan adalah kebutuhan afiliasi.

McClelland (1987) menyimpulkan kebutuhan afiliasi yaitu kemauan dari beberapa individu untuk mencari atau menjalin hubungan persahabatan dengan orang lain tanpa memandang status, jabatan maupun pekerjaan, kedudukan. Individu dengan kebutuhan untuk berafiliasi yang tinggi yaitu seseorang yang berusaha mendapatkan persahabatan. Individu tersebut akan berusaha untuk menghindari konflik. Makin besar keinginan untuk bergaul maka semakin mudah seseorang dipengaruhi oleh kelompok sosial.

Individu tidak akan dapat menjalani kehidupannya tanpa kehadiran orang lain, karena pada hakekatnya, individu mempunyai kebutuhan untuk hidup bersama dengan orang lain yang tentu saja kebutuhan tersebut tidaklah sama antara individu yang satu dengan yang lain. Kebutuhan ini tercermin pada keinginan untuk bersahabat dan berinteraksi dengan orang lain dan keinginan untuk mempertahankan hubungan yang terjalin dengan baik. Kebutuhan afiliasi biasanya diusahakan agar terpenuhi melalui kerjasama dengan orang lain, membantu orang lain, dan sebagainya.

Pada dasarnya kebutuhan ini akan mempengaruhi seseorang dalam berkomunikasi secara efektif agar terjalinnya hubungan yang akrab. Tak mungkin pula kebutuhan individu akan terpenuhi tanpa andil dari orang di sekitar kita, oleh karena itu, kebutuhan afiliasi ini sangat penting dan vital bagi kehidupan manusia khususnya bagi kalangan remaja.

Terkhususnya bagi remaja kebutuhan afiliasi ini sangatlah penting karena pada usia remaja akan mengalami kematangan secara fisik, maupun psikis sebelum menginjak pada usia dewasa. Sering kali ditemukan hubungan yang akrab menjadi retak karena adanya kesalah pahaman yang terjadi antara yang mengajak bicara dan diajak bicara, menyebut dengan panggilan yang tidak selayaknya, dan sebagainya.

Siswa pada SMP N 1 Bandungan Kabupaten Semarang ini telah mencapai usia-usia remaja yang notabene usia remaja adalah usia dimana individu membutuhkan kebutuhan afiliasi yang tinggi. Dengan sistem sekolah diharapkan 
remaja yang menempuh pendidikan dapat memahami arti silahturahmi dan mencerminkan perilaku, sikap atau nilainilai sosial sehingga kebutuhan afiliasi akan terpenuhi

Berdasarkan wawancara dengan guru BK dan melihat langsung di lokasi didapatkan hasil di kelas VIII SMP Negeri 1 Bandungan Kabupaten Semarang terdapat masalah afiliasi yaitu situasi yang bersifat psikologik (bimbang/tidak yakin dengan pendapatnya), perasaan dan kesamaan (kesamaan kelompok entik/membentuk kelompok). Contohnya di SMP N 1 Bandungan Kabupaten Semarang peserta didik banyak yang merasa ragu mengungkapkan pendapatnya jika salah akan ditertawakan teman-temannya, ada banyak peserta didik di SMP $\mathrm{N} 1$ Bandungan Kabupaten Semarang yang berasal bukan dari daerah sekitar sekolah dengan gaya berbicara yang keras atau bukan orang jawa.

Selain itu ada penelitian yang menunjang yang diteliti oleh Bagus Tri Setia Laksana (2010) melakukan penelitian yang bertujuan untuk mengetahui hubungan komunikasi interpersonal dengan kebutuhan afiliasi pada remaja di MTS Darul Ulum Waru Sidoarjo. Penelitian dilakukan pada 270 siswa dengan menggunakan metode kuantitatif dengan menggunakan skala sebagai alat ukur. Berdasarkan analisis hasil penelitian diketahui bahwa hubungan komunikasi interpersonal dengan kebutuhan afiliasi diperoleh hasil korelasi sebesar 0,271 yang berarti hubungan antara komunikasi interpersonal tidak terlalu berpengaruh besar atau bisa dikatakan rata-rata, mungkin ada faktor-faktor lain yang mempengaruhi seseorang untuk berkomunikasi dengan orang lain.

Berdasarkan uraian tersebut penulis tergugah untuk meneliti tentang hubungan antara komunikasi interpersonal dengan kebutuhan afiliasi siswa kelas VIII SMP N 1 Bandungan Kabupaten Semarang.

\section{KAJIAN PUSTAKA}

\section{Kebutuhan Afiliasi}

McCelland (1987) berpendapat bahwa kebutuhan afiliasi ialah "kebutuhan akan kehangatan, dan sokohan dalam berhubungan dengan orang lain. Daripada itu kebutuhan afiliasi ini mengarahkan tingkah laku untuk menciptakan hubungan yang akrab dengan orang lain."

Murray (dalam Maslow., 2004) kebutuhan afiliasi adalah "kecenderungan untuk membentuk pertemanan dan untuk bersosialisasi, untuk beriteraksi secara dekat dengan orang lain, untuk bekerja 
sama dan berkomunikasi dengan orang lain dengan cara bersahabat, dan untuk jatuh cinta."

Bersumber pada pendapat di atas dapat dinyatakan bahwa kebutuhan afiliasi adalah suatu keinginan seseorang untuk mencapai komunikasi dengan orang lain dengan tujuan mencari hubungan yang dekat dengan orang lain.

Sears, Freedman, dan \& Peplau (1994) menyebutkan bahwa ada empat alasan mengapa manusia berafiliasi dengan orang lain.

a. Insting, sifat-sifat berkelompok yaitu insting yang dibawa sejak lahir melalui genetika.

b. Pembawaan, salah satu keunikan dari manusia agar tetap hidup adalah keinginan berafiliasi.

c. Belajar, manusia lahir dalam kondisi tidak berdaya dan hidupnya bergantung kepada orang lain.

d. Kebutuhan, banyak kebutuhan yang hanya dapat terpuaskan saat berhubungan dengan orang lain, mengibaratkan kebutuhan bekerjasama, diterima, dan kasih sayang.

Menurut McCelland (1987) orangorang yang mempunyai kebutuhan afiliasi yang tinggi berikut aspek-aspeknya:

a. Lebih suka bersama orang lain daripada sendirian
Seseorang yang memiliki kebutuhan afiliasi tinggi lebih suka bersama teman-temannya. Hal ini berlandaskan lantaran manusia adalah makhluk sosial. Sedangkan pada remaja adalah usia dimana remaja ingin terlepas dari lingkungan keluarga khususnya orang tua. Seseorang yang memliki kebutuhan afiliasi rendah cenderung lebih suka melakukan aktifitas sendirian dari pada dengan orang lain.

b. Sering berinteraksi dengan orang lain Kecenderungan individu untuk mencari lingkungan baru dan memperbanyak teman secara otomatis membuat individu lebih banyak berinteraksi dengan orang lain atau senang bergaul. Sedangkan individu dengan kebutuhan afiliasi rendah lebih sedikit berinteraksi dengan orang lain

c. Ingin disukai dan diterima orang lain Seseorang yang mempunyai kebutuhan afiliasi tinggi memiliki dorongan dari keinginan remaja yaitu untuk diakui orang lain dan untuk meningkatkan harga diri. Tidak demikian berarti individu yang berkebutuhan afiliasi rendah tidak ingin diterima orang lain, tetapi mereka kurang aktif untuk 
mengajukan eksitensi mereka agar disukai dan diterima orang lain.

d. Menyenangkan hati orang lain

Keinginan individu yaitu untuk mendapatkan pengakuan dari lingkungan dimana ia berada. Seorang remaja berkebutuhan afiliasi tinggi berusaha untuk menjadi pribadi yang menyenangkan untuk orang lain. Seseorang yang berkebutuhan afiliasi rendah cenderung lebih acuh terhadap pendapat orang lain.

\section{Komunikasi Interpersonal}

Menurut Lunandi

(2003)

komunikasi merupakan "usaha manusia dalam pergaulannya dalam menyampaikan kepada orang lain, pikiran, isi hati, serta kebutuhan orang lain yang bersangkutan dengan diri kita."

Hardjana (dalam Devito., 2011) komunikasi interpersonal merupakan "interaksi tatap muka antara dua atau beberapa orang, dimana pengirim dapat menyampaikan pesan secara langsung, dan penerima dapat menanggapi secara langsung.

Maka dapat disimpulkan bahwa komunikasi interpersonal adalah komunikasi yang dilakukan segera antara dua atau tiga orang secara tatap muka untuk menyampaikan pesan secara langsung.
DeVito (2011) berpendapat ada beberapa aspek dalam komunikasi interpersonal agar komunikasi dapat berjalan dengan baik yaitu:

a. Keterbukaan

Kondisi mental yang sehat dan tidak sehat ternyata dipengaruhi juga oleh kualitas komunikasi interpersonal dengan orang lain. Keterbukaan atau sikap terbuka sangat berpengaruh dalam menumbuhkan komunikasi interpersonal yang efektif. Keterbukaan adalah pengungkapan reaksi atau tanggapan seseorang terhadap situasi yang sedang dihadapi serta memberikan atauu tanggapan situasi yang sedang dihadapi serta memberikan informasi tentang masalalu yang relevan untuk memberikan tanggapan seseorang masa kini.

b. Empati

Empati sebagai kemampuan seseorang untuk mengetahui apa yang sedang dialami orang lain pada suatu saat tertentu. Komunikasi interpersonal dapat berlangsung kondusif apabila komunikator (pengirim pesan) menunjukan rasa empati pada komunikan (penerima pesan). Empati dapat diartikan sebagai menghayati perasaan orang 
lain atau turut merasakan apa yang dirasakan orang lain. Dalam berempati seseorang memiliki perasaan yang sama dengan kondisi yang dialami orang lain.

c. Dukungan

Hubungan interpersonal yang efektif adalah hubungan dimana terdapat sikap mendukung (suportive). Maksudnya satu sama lainnya saling memberikan dukungan terhadap pesan yang disampaikan. Komunikasi interpersonal diperlukan sikap memberikan dukungan dari pihak satu dengan yang lain. Hal ini senada dengan yang dikemukakan Sugiyono (2005) dalam komunikasi interpersonal perlu adanya suasana yang saling medukung atau memotivasi satu sama lain.

d. Sikap Positif

Sikap positif merupakan kecenderungan seseorang untuk mampu bertindak berdasarkan penilaian yang baik tanpa merasa bersalah yang berlebihan, menerima diri sebagai orang yang penting dan bernilai bagi orang lain. Memiliki keyakinan atas kemampuan untuk mengatasi persoalan, peka terhadap kebutuhan orang lain pada kebiasaan sosial yang telah diterima. Memberi dan menerima pujian tanpa pura-pura memberi dan menerima penghargaan tanpa merasa bersalah.

e. Kesetaraan

Kesetaraan merupakan perasaan sama dengan orang lain, sebagai manusia tidak tinggi atau rendah, walaupun terdapat perbedaan dalam kemampuan tertentu, latar belakang keluarga atau sikap orang lain terhadapnya.

\section{METODE PENELITIAN}

Penelitian ini menggunakan jenis penelitian korelasional. Populasi dalam penelitian ini adalah siswa kelas VIII SMP N 1 Bandungan. Sampel yang digunakan dalam penelitian ini adalah dengan menggunakan total sampling yaitu mengambil seluruh siswa kelas VIII SMP N 1 Bandungan yang berjumlah 140 siswa.

Dalam penelitian ini terdapat 2 variabel yaitu variabel bebas dan variabel terikat. Variabel independen (bebas) dalam penelitian ini yaitu Komunikasi Interpersonal (X) dan Variabel dependen (terikat) dalam penelitian ini yaitu Kebutuhan Afiliasi (Y).

Hasil uji validitas diperoleh hasil bahwa komunikasi interpersonal (X) yang valid ada 32 item. Item-item pernyataan tersebut mempunyai koefisien corrected item to total correlation sebesar 0,417-0,823 dengan reliabilitas 
sebesar 0,964 yang berkategori sangat bagus. Kebutuhan Afiliasi (Y) yang valid ada 35 item. Item-item pernyataan tersebut mempunyai koefisien corrected item to total correlation sebesar 0,402 0,844 dengan reliabilitas sebesar 0,966 yang berkategori sangat bagus.

\section{HASIL DAN PEMBAHASAN}

\section{Analisis Deskripsi Komunikasi Interpersonal}

Berdasarkan distribusi frekuensi frekuensi dapat diketahui bahwa komunikasi interpersonal yang dimiliki oleh siswa kelas VIII SMP $\mathrm{N} 1$ Bandungan sebagian besar berada dalam kategori sedang dengan persentase sebesar $37,14 \%$.

\section{Analisis Deskripsi Kebutuhan Afiliasi}

Berdasarkan distribusi frekuensi frekuensi dapat diketahui bahwa kebutuhan afiliasi yang dimiliki oleh siswa kelas VIII SMP N 1 Bandungan sebagian besar berada dalam kategori sedang dengan persentase sebesar $40 \%$.

\section{Analisis Korelasi}

Tabel 1. Korelasi

\begin{tabular}{|c|c|c|c|c|}
\hline \multicolumn{5}{|c|}{ Correlations } \\
\hline & & & $\begin{array}{l}\text { Kbthn } \\
\text { Afiliasi }\end{array}$ & $\begin{array}{c}\text { Kmnkasi } \\
\text { Interperso } \\
\text { nal }\end{array}$ \\
\hline $\begin{array}{l}\text { Kend } \\
\text { all's } \\
\text { tau__ } \\
\text { b }\end{array}$ & $\begin{array}{l}\text { Kbthn } \\
\text { Afiliasi }\end{array}$ & $\begin{array}{l}\text { Correlati } \\
\text { on } \\
\text { Coefficie } \\
\text { nt } \\
\text { Sig. (2- } \\
\text { tailed) } \\
\text { N }\end{array}$ & 140 & $\begin{array}{r}, 976^{* *} \\
, 000 \\
140\end{array}$ \\
\hline
\end{tabular}

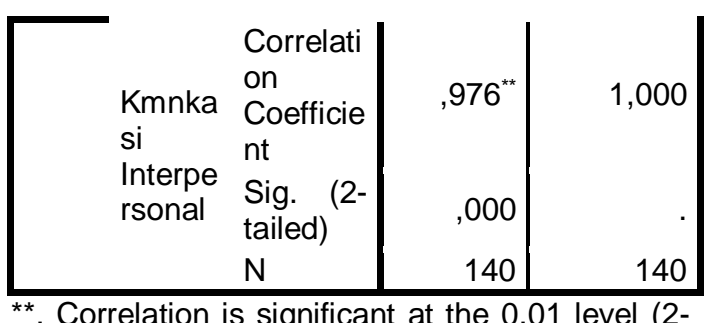
tailed).

Berdasarkan hasil uji korelasi diatas maka diketahui nilai $r_{x y}=0,976$ dengan koefesien signifikansi 0,000 $<0,01$ dengan demikian dapat ditarik kesimpulan bahwa ada hubungan positif dan signifikan antara komunikasi interpersonal dengan kebutuhan afiliasi. Artinya semakin tinggi komunikasi interpersonal maka semakin tinggi pula kebutuhan afiliasi peserta didik. Atau sebaliknya semakin rendah komunikasi interpersonal peserta didik, maka semakin rendah tingkat kebutuhan afiliasi yang dilakukan oleh peserta didik. Menurut Sugiyono (2011) koefisien korelasi 0,976 menunjukkan tingkat hubungan yang sangat tinggi.

Berdasarkan uji hipotesis yang telah dilakukan, menunjukkan hasil bahwa terdapat hubungan positif dan signifikan antara komunikasi interpersonal dengan kebutuhan afiliasi. Diketahui koefisien hubungan antara komunikasi interpersonal dengan kebutuhan afiliasi sebesar 0,976 dengan demikian hipotesis diterima dan berbunyi bahwa terdapat hubungan yang signifikan antara komunikasi interpersonal dengan 
kebutuhan afiliasi siswa Kelas VIII SMP N 1 Bandungan Tahun Pelajaran 2018/2019.

Berdasarkan hasil penelitian ini maka penelitian ini mendukung pernyataan Bagus Tri Setia Laksana (2017) dan Lasut, F. X. Gerald (2012) komunikasi interpersonal adalah "komunikasi yang dilakukan dua atau tiga orang secara tatap muka untuk menyampaikan pesan secara langsung”. Karena seseorang dalam komunikasi harus bisa menyampaikan isi pesan yang ingin disampaikan dengan cara yang tepat, cermat dan jelas agar bisa diterima dengan baik tujuan dari pesan itu. Dalam komunikasi sering terjadi kesalahpahaman, adanya kesalahpahaman yang terjadi antara remaja dalam komunikasi, merupakan salah satu, indikasi sulitnya melakukan komunikasi interpersonal.

McCelland (1987) kebutuhan
afiliasi adalah "kebutuhan akan
kehangatan, dan sokohan dalam berhubungan dengan orang lain. Daripada itu kebutuhan afiliasi ini mengarah tingkah laku untuk menciptakan hubungan yang akrab dengan orang lain".

Besarnya koefisien hubungan di atas dapat diartikan bahwa variabel $\mathrm{X}$ skornya rendah, dan variabel Y skornya tinggi. Berdasarkan hasil tersebut, bisa diartikan semakin tinggi kebutuhan afiliasi maka semakin tinggi komunikasi interpersonal yang terjadi. Demikian pula sebaliknya semakin rendah kebutuhan afiliasi maka semakin rendah komunikasi interpersonal yang terjadi. Karena ketika kebutuhan tinggi peserta didik bisa melakukan komunikasi dengan orang lain, hal ini menyebabkan hubungan yang baik dengan orang lain maka komunikasi interpersonal yang dihasilkan semakin tinggi dikarenakan peserta didik yang sudah mempunyai kebutuhan afiliasi yang tinggi akan mempunyai hubungan yang baik terhadap orang lain sehingga komunikasi interpersonal yang dihasilkan juga tinggi.

Hasil penelitian diatas mendukung penelitian yang dilakukan oleh: Laksana, Bagus Tri Setia (2010) hubungan komunikasi interpersonal dengan kebutuhan afiliasi pada remaja di MTs Darul Ulum Waru-Sidoarjo. Hasil penelitian menunjukan bahwa ditemukan korelasi yang signifikan antara komunikasi interpersonal dengan kebutuhan afiliasi, hal ini dapat dilihat dari besarnya signifikansi $0,036<0,05$.

Dan hasil penelitian dari Lasut, F. X. Gerald (2012) hubungan antara komunikasi interpersonal dan kebutuhan afiliasi pada remaja pengguna facebook. Hasil penelitian menunjukan bahwa 
ditemukan hubungan yang signifkan antara komunikasi interpersonal dengan kebutuhan afiliasi sebesar $(\mathrm{r}=0,458)$ dengan taraf signifikan sebesar 0,000 $(\mathrm{p}<0,01)$.

\section{PENUTUP}

\section{Simpulan}

Dari hasil penelitian mengenai hubungan antara komunikasi interpersonal dengan kebutuhan afiliasisiswa kelas VIII SMP $\quad \mathrm{N} \quad 1$ Bandungan Kabupaten Semarang Tahun Ajaran 2018/2019 ditemukan bahwa terdapat hubungan yang signifikan. Hal ini ditunjukkan dengan diketahui nilai $\mathrm{r}_{\mathrm{xy}}$ $=0,976$ dengan koefesien signifikansi $0,000<0,01$. Dapat dikatakan bahwa semakin tinggi kebutuhan afiliasi seseorang maka semakin tinggi pula tingkat komunikasi interpersonal dalam hubungan sosialnya.

\section{Saran}

Guru diharapkan mampu memberikan suatu layanan bimbingan konseling secara lebih variatif agar dalam menyelesaikan masalah. Kegiatan yang dapat dilakukan guru bimbingan konseling adalah menyisipkan metode permainan kelompok dalam memberikan layanan, membuat penugasan yang melibatkan kelompok (sosiodrama dan psikodrama) agar peserta didik saling berinteraksi dengan teman lainnya dengan begitu tercipta kebutuhan afiliasi yang muncul dari peserta didik kemudian terjadi komunikasi yang optimal antar peserta didik.

Peserta didik diharapkan mampu menyalurkan kebutuhan afiliasinya sehingga meminimalisasi dampak negatif yang ditimbulkan dari tidak berkomunikasi dengan orang lain. Perlu diketahui kita adalah makhluk sosial yang tidak bisa hidup sendiri tanpa orang lain.

Sekolah diharapkan bisa memberikan wadah untuk para siswasiswinya agar dapat meningkatkan komunikasi interpersonal di lingkungan sekolah sehingga kebutuhan akan afiliasi dapat meningkat

\section{DAFTAR PUSTAKA}

Christiani, Lydia. 2017. Deskripsi kemampuan komunikasi interpersonal siswa kelas VIII santo aloysius turi Tahun ajaran 2016/2017 dan implikasinya terhadap usulan topik-topik bimbingan pribadi-sosial. Yogyakarta:

https://www.google.com/url?sa=t \&source=web\&rct=j\&url=https://r epository.usd.ac.id/15675/2/12111 4016_full. (Diunduh 8 Januari 2019)

Laksana, Bagus Tri Setia. 2010. Korelasi Antara Komunikasi Interpersonal dengan Kebutuhan Afiliasi pada Remaja di MTs Darul Ulum Waru-Sidoarjo. Surabaya: http://digilib.uinsby.ac.id/id/eprint 122238._(Diunduh 8 Januari 2018) 
Lasut, Gerarld F, X. 2012. Hubungan Antara Komunikasi Interpersonal Dan Kebutuhan Afiliasi pada Remaja Pengguna Facebook. Jakarta:

https://library.gunadarma.ac.id/rep ository/view/3753430_.(Diunduh 8 Januari 2019)

Layla, Yanica Nur. 2014. Korelasi Antara Kebutuhan Afiliasi dan Keterbukaan Diri dengan Intensitas Menggunakan Jejaring Sosial pada Siswa Kelas VIII SMP Negeri $15 \quad$ Yogyakarta. Yogyakarta: journal.student.uny.ac.id/jurnal/art ikel/9224/90/985. (Diunduh 15 November 2018)

Lunandi, A. G. 2003. Komunikasi Mengena: Meningkatkan Komunikasi Antar Pribadi. Yogyakarta: Kanisius

Maslow, A. 2004. Psikologi Sains: Tinjauan Kritis terhadap Psikologi Ilmuwan \& Ilmu Pengetahuan Modern. Jakarta Selatan: Teraju

McClelland, David C. 1987. The Achieving Society. New york: D. Van Nostrand Company, Inc.

Sears, David O., Freedman, Jonathan L., \& Peplau, L., A (1994). Psikologi Sosial jilid 2. Alih Bahasa: Michael Adryanto. Jakarta: Erlangga

Sugiyono. 2011. Metode Kuantitatif, Kualitatif dan $R \& D$. Bandung: Alfabeta 